\title{
Portion of Heterogeneous Resources of an IoT Gadget to Flexible Services
}

\author{
C. Geetha, S. Kavitha, C. Nalini
}

\begin{abstract}
Internet of Things (IoT) gadgets can be set up with exquisite heterogeneous framework interfaces. An overwhelmingly huge share of companies can also call for a couple or those interfaces' open belongings. as a result, we gift an correct numerical arrangement of consigning agencies to interfaces with heterogeneous resources in any event one rounds. for affordable version sizes, the displayed definition produces ideal publications of motion for this computationally tough hassle. We display the NP-Completeness of the issue and make figurings to appraise the proper reaction for extraordinary model sizes. the principle figuring allocates the most citing business enterprise necessities to start with, brooding about the everyday charge of interfaces assets. The subsequent one unearths out the bringing up useful aid shares and designates the most mentioning of them first through deciding on erratically amongst as alternative mentioning offers. Finally, we deliver propagation comes about giving facts into companies component completed particular interfaces for the 2 times.
\end{abstract}

\section{Keywords: GADGET, Communications generation}

\section{INTRODUCTION}

A.Over the current couple of years we've got were given seen the inventive trade addressed with the aid of the internet of things (IoT) [2]. Incalculable with special capacities for example, sensors, actuators, remarkable subjects, and servers can interconnect and provide climb to the headway of persuading agencies and packages. every IoT contraption can be appeared as an component-middle factor of a computerized bodily herbal framework with the functionality to effectively partake and make its advantages open in solicitation to accomplish a many-sided intention i.e., the execution of at least one errands alloted to the framework [3]. however open property (like minded imperativeness, coping with control, collecting capacities, and so on.) are continuously obliged, IoT gadgets can be drawn inside the path of offer a huge association of corporations. Unmistakably a successful section of these IoT assets would possibly decorate the execution of this framework. perfect useful resource assignment for IoT is not piddling considering its scattered and heterogeneous nature. on this paper we expect that an IoT tool includes excellent framework interfaces of heterogeneous generation. We recollect that each one of them has a recreation plan of non-real.

Revised Manuscript Received on August 22, 2019.

C. Geetha, Department of CSE, Bharath Institute of Higher Education and Research, Chennai, Tamilnadu, India.

S. Kavitha, Department of CSE, Bharath Institute of Higher Education and Research, Chennai, Tamilnadu, India.

C. Nalini, Department of CSE, Bharath Institute of Higher Education and Research, Chennai, Tamilnadu, India.

\section{RELATED WORK}

Heterogeneity of frameworks employer systems with numerous and various interfaces has been extensively mulled over. Present applications in 4G/wireless heterogeneous far off frameworks, associated with this work, are confirmed in [4]. In that, the makers display systems for offloading endeavors, for instance, dissent confirmation in a motion of pics, capabilities planning, and figuring descriptors to liven up the favored errands and retaining up a key precise techniques from movement over-load. Correspondingly, the makers of [five] advise a framework to disperse substance, as an instance, casual association revives, sees, furthermore, records continues. A shape for sturdy frameworks agency, considering further free area Optic (FSO) affiliations and Optical Fibers, is established in [6]. useful resource Allocation (RA) has been significantly inspected in some distance off frameworks. In [7], models that catch the move-layer association from the physical to move layers in far flung kind out systems, as an instance, mobile, uncommonly named and sensor organizes and furthermore aggregate topologies are showed. those models do not forget the time changing nature of self-confident frameworks with specific motion sending modes, at the side of datagrams besides, virtual circuits. statistics and Communications generation (ICT) systems also can apportion property as shown with the resource of some execution estimations, as an example, functionality and equity [eight, nine], or in mindset on motion compose [10]. Such targets can commonly be conflicting and it can be hard to at the identical time gather them to an desirable enough diploma [9]. Ismail et al. have too dispersed a work in which reliable and variable piece charge agencies with necessities are visible as [eleven], to the form of diploma, that every framework gives a higher want without any special person supporters in preference to severa customers. A case IoT software program with excessive solicitation constraints over property for serve severa clients is displayed in [12]. The proposed framework is likewise affordable to various RA settings as it clothing methods to deal with orchestrate customers with dispose of inclinations using in reality compelled data. An appropriated show in moderate of records is proposed in [17] to comprehend the RA trouble and commercial enterprise organisation in IoT heterogeneous frameworks. This show is brilliant to affiliation or middle factor frustrations in one among a kind events.

In that paper, an IoT situation is given middle factors figuring out with a given IoT challenge with the useful resource of converting their assignment

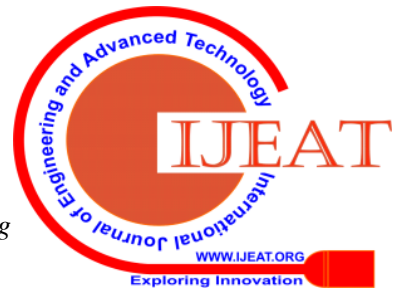


repeat and pad inhabitance. Variable channel situations and customers' solicitations be part of RA to quality of company (QoS) necessities and accreditations. The research has supplied severa focuses on dealing with RA. For case, Tan et al. [thirteen] show strategies and figurings to raise set up software for 3 differing QoS essential conditions. The conventional QoS attributes, for example, throughput, deferment and jitter are not thru any way in form to IoT, however as an alternative can even now be applicable depending upon the software [14-16]. As such, the QoS in IoT is up 'til now not all round portrayed, in a popular feel in mild of the manner that an IoT advantage can not be defined due to the fact the easy obtainment and getting ready of facts and the vital authority approach in identity moreover, correspondence [17]. In IoT, more QoS developments, as an instance, information exactness, protection, and favorability which depend on a surely fundamental level on the steadfastness of the framework accessibility, availability of contraption imperativeness, and elegant assets may additionally furthermore altogether depend quantity $[18,19]$. moreover, some IoT businesses are required to be reconfigurable what's step by step, composable. Li et al. [20] propose a 3-layer QoS booking version for QoS-careful IoT gain. at the software program layer, the QoS plan scheme researches best benefit sythesis thru the usage of the studying gave through each benefit. Present day-day makes use of of RA can be found in [21], wherein the impact of among consumer impedance in wireless frame Sensor Networks (WBSNs) is inspected. The heterogeneity of IoT gadgets and the benefits they provide for making IoT applications are at the focal point of our paintings. late compositional frameworks (see e.g., [22, 23] and the references in that) call for de-verticalization of exercise plans, with packages being delivered, unreservedly of the forestall gadgets, which may be some thing from a sensor to the cutting-edge wi-fi. We revolve round IoT finding out devices having brilliant, specific interfaces, all of which methodologies a social event of constrained heterogeneous assets, as an example, downlink information fee, pad vicinity, CPU interrupts, and so on. We furthermore think about that every commercial enterprise agency is depicted by means of a route of movement of solicitations that can be served by means of manner of the use of the advantages to be had on one contraption's interfaces. looking in advance to a middleware has viably doled out an commercial enterprise corporation onto a given contraption, in this work we address the problem of adaptably mapping the enterprise agency resource wishes onto the interfaces of that tool.

We do not forget a path of motion of interfaces $I=1$, I. The interfaces are portrayed via a hard and fast ok $=1, \ldots, \mathrm{k}$ of advantages related to them (as an example CPU cycles, downlink facts rate, bolster measure). We anticipate that each business enterprise $\mathrm{j} \in \mathrm{J}=1, \mathrm{~J}$ is hooked up with a good enough-dimensioned demand complete variety vector $\mathrm{dj}$. In like way, every interface has a ok-dimensioned restrict (useful aid availability) whole extensive range vector bi. We undergo in thoughts the case that corporations are flexible as in they'll be diagnosed by the usage of way of detail their solicitations on numerous interfaces. to show the burden this is restricted on the working plan of the contraption to control such additives, we gift a settled fee trouble: the inception fee in line with interface. this is used as a parameter to check the quantity of components. close to this settled fee, we also consider an usage fee for each unit of gain used on an interface. sooner or later, to particular the problem, we make the supposition that the given task is feasible i.e., as a long way as feasible are suitable sufficient to serve the asked solicitations, which can be conveyed as $\mathrm{Xj} \in \mathrm{J} \mathrm{Xk} \in$ good enough $\mathrm{djk} \leq \mathrm{Xi} \in \mathrm{IXk} \in$ ok bik, $\forall$ good enough $\in$ adequate.

The Partition trouble (PP) shows settling if, however the whole thing that a path of movement of $\mathrm{N}$ whole numbers, of elegant $\mathrm{S}$ may be isolated into subsets, every having an combination of $\mathrm{S} / 2$. The PP is a popular NP-entire problem [24]. We construct the evidence in mild of the improvement of a case of the problem from any occasion of the Partition problem, as takes after. famend that we have got fine a solitary resource create at the interfaces available (good enough $=1)$. provide every segment get to the sport plan of the PP be an enterprise of the SIA trouble case and the estimation of every section be the gain solicitation dj of the pertaining to $j$-th gain additionally, allow there be simply interfaces $(I=2)$, every with useful resource openness $b i=S / 2, \forall i \in 1,2$. We set the overhead coefficients to $0 \mathrm{ij}=$ zero, $\forall \mathrm{i} \in 1,2, \forall \mathrm{j} \in 1, \ldots, \mathrm{J}$ and the utilization fee to attention in like way cij $=0$, at the same time as we settle the interface activation price to as a minimum one: Fij $=1$. The created SIA occasion is viable, in moderate of the manner that (I) by way of manner of the usage of improvement the whole resource availability on the 2 interfaces works to serve the whole solicitation and (ii) component benefit demand on multiple interfaces is permitted. Recollect an answer of the created SIA situation wherein no elements occur. In case this sort of solution exists, with the resource of then each agency is consigned to at the least one interface and through (1) the rate might be similar to J. Plus, while you do not forget that any business enterprise break up in two interfaces gives an charge of , if elements exist in a solution, the price might be at any fee $\mathrm{J}+1$. hence, with the aid of the improvement of the occasion, it advances toward carrying out obvious that no regard lower than $\mathrm{J}$ can be cultivated. The affirmation version of the SIA event is to reply whether or not or not or no longer or but now not there is a reaction for which the fee is at thru and large multiple regard, for our state of affairs J. In any route of motion of the SIA the corporation call for allotted on each interface can be $S / 2$. If there is no piece of corporations in an answer, thru then their assignment to the 2 interfaces is a fraction of the numbers within the PP with meet entirety. alongside those traces, in case the reaction to the number one PP case is positive and we layout companies to the segments of the route of movement subsets, by means of the use of then through manner of consigning the companies to the 2 interfaces, no components will exist and the fee might be J. mapping to the segments of the path of movement subsets as a result, the response to the affirmation adjustment of the SIA event is sure. as an alternative, if the response to the SIA is really,

by using then there cannot be a phase advantage so the project of companies to the two interfaces is a giant PP course of movement. Thusly, lights up the created SIA case are equal to disentangling a self-self-confident PP occasion. A example detail has been depicted in Fig. 1. groups demand three one in each of a kind assets of an IoT device's interfaces. 


\section{RESULT AND DISCUSSION}

We've one-of-a-kind computations which predicted the right sport plan of SIA. the two counts apportion benefit solicitations to interfaces' capacities the usage of interfaces' utilization and graduation charges $\mathrm{c}$ and $\mathrm{F}$ independently. they vary in the manner they choose out which beneficial useful resource solicitation to serve first. The same old concept of the principle estimation, which we call RANDINIT-Allotment, is to first of all serve the organizations that solicitation the maximum raised resource stocks. Serving the most raised dreams first will use the finest percentage of the bottom steeply-priced interface limits. on this manner, it's miles notably viable that the total fee can be constrained. The depend via then maintains serving the solicitations with lessen down useful resource offers and so on. The serving mastermind amongst parallel beneficial useful resource gives is picked erratically. The underlying four traces of the depend (see algorithm 1) parent the benefit gives of every solicitation. They do all matters taken into consideration thru parceling each solicitation thru the maximum outrageous useful resource solicitation of its compose. The cease result is an institutionalized solicitations enterprise $\mathrm{d}^{\prime}$. alongside the ones traces, zero $\leq \mathrm{d}^{\prime} \quad \mathrm{jk} \leq 1$, $(\forall \mathrm{j} \in \mathrm{J}), \quad(\forall \mathrm{ok} \in \mathrm{ok})$. Framework RANDOM-INIT-identical-stocks in Line 5 of the computation takes $\mathrm{d}^{\prime}$ as information and famous which groups solicitation ascend to useful resource stocks. For the ones businesses it aimlessly options the solicitation via which they'll be served. The end result is a vector (ds) with the solicitation with the aid of using which the solicitations can be served. given that there may be thru and via manner of a facts shape (ds) with the bringing up of the solicitations, RAND-INIT-ALLOCATION can maintain with each solicitation of ds beginning from the primary, and dole out it to the open interface assets. The instatement of partner additives follows in lines $6-7$. the whole rate is saved into variable totalCost. From the begin, the second show A consists of $\mathrm{I} * \mathrm{~J}$ zero factors. some time later, phase Aij is probably set to at least one if gain $\mathrm{j}$ has legal interface $\mathrm{I}$. The little little bit of traces eight -23 conveys every business enterprise name for ds to the interfaces, beginning by manner of serving the maximum mentioning one first. in any case, the rely discovers which advantage $\mathrm{j}$ asked useful useful aid ok (Line 9) mapping the vector ds to the second headings of djk. by using using then, it searches for the 2 interfaces with the maximum reduced use costs in step with unit. The concerning data are stored into additives $i^{\prime}$ and that $i^{\prime}$ ' (strains 10 and eleven). subsequent, it attempts to appropriate the solicitation to the most sensible - by manner of the use of use price in line with unit - interface. In case as an extended way as possible are ok (Line 12), with the aid of the use of then the thing takes location thru the ALLOCATE method: the elements of confinement are lessened as it ought to be thru the requested solicitation, the totalCost is revived, and the twofold element $A\left(i^{\prime}, j\right)$ is ready to 1 to suggest that employer $\mathrm{j}$ has ordered interface $\mathrm{i}^{\prime}$. If the lowestcost interface ( $\mathrm{i}^{\prime}$ ) can not serve ds, via then the computation tries to apportion it to the interface with the accompanying least use value constant with unit $\left(\mathrm{I}^{\prime}{ }^{\prime}\right)$ ), following the right detail steps (lines $14-15$ ). inside the event each of these undertakings bypass over the mark, RAND-INITALLOCATION investigates the danger of component the asked gain needs into at any price interfaces (lines sixteen-22). costs are figured for this circumstance. NON-SPLITCOST reveals out the fee of dispensing the requestsOn the far flung opportunity that that the two most diminished rate interfaces can clearly to a limited volume serve the solicitation, the $1 / 3$ maximum practical interface is secured and so on. As such, the base of those fees (Line 19) shows the solicitation partition (strains 19-22). subsequently, after each solicitation has been served, the incitation price is added to the totalCost, with the aim that this variable shops the real overall charge of the ensuing assignments (Line 23).

To survey the impact of the randomized guarantee of strains 1 -five, we in like manner brought a complex mentioning thinking about the standard price of the asked needs in deciding on which useful resource solicitation to serve first. Figuring 2 indicates this variety, which we named common-cost-ALLOCATION. the modern computation differentiates inside the solicitation it serves the requested resource dreams. within the wake of performing name for institutionalization as RAND-INIT-ALLOCATION (traces 1 - four), the AVERAGECOST-Distribution determines the everyday rate of every gain shape via conveying the contact aftereffect of (detail) vectors ck and bk, which cope with okay-th useful aid's utilization were given (according to unit) and cutoff elements over all interfaces independently (lines 5 - 7). on this way, detail ( $\mathrm{j}$, okay) of bypass phase $\mathrm{C}$ will preserve the same old price of gain adequate; thusly for a settled right enough, the regard of $\mathrm{Cjk}$ is the equal for each $\mathrm{j}$. Line eight conveys the detail sharp Hadamard) final results of move sections $d^{\prime}$ and $\mathrm{C}$. the following segments djk of grid $\mathrm{d}$ will maintain the usual fee of the stated useful beneficial useful resource properly enough of enterprise $\mathrm{j}$. As a stop result, we are able to use the statistics of matrix reshape and sort the given toolaround there, we inventory the concept of credibility in a solitary round. In case the mission of all solicitations cannot take set up a novel shot (or spherical),

we reflect onconsideration on that we are in a position to utilize a comparable interface limits concerning multiple spherical to manipulate the the rest of the benefit needs. As such, inside the anyways spherical we make a divided bit (that won't serve all solicitations) and while these solicitations were served we all all over again use similar interfaces' benefits for each exclusive round to serve the the rest of the solicitations reiterating this approach for indistinguishable variety of rounds from key. This important plan may be finished through displaying a whole variety $\mathrm{R}>1$ at the way to be the quantity of rounds to serve all solicitations with as a protracted way as viable. We call this trouble multi-spherical SIA and the refinement from SIA is surely in (three), which currently advances in the direction of getting to be:

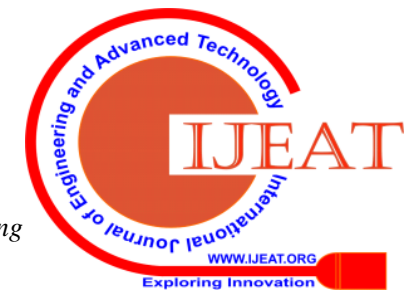


$\mathrm{Xj} \in \mathrm{J}(1+$ aijk)xijk $\leq$ Rbik, $\forall \mathrm{i} \in \mathrm{I}, \forall$ good enough $\in$ ok. (6) The warranty of $\mathrm{R}$ relies upon upon the form originator's goal. the quantity of rounds are suffering from the going with elements: customer versatility as opposed to charge of the game plan, and client flexibility as opposed to time period of the course of movement (i.e., large type of rounds). Especially, if an organizer is uncaring to the quantity of rounds, through then in each round the maximum diminished price beneficial useful resource can be assigned. alternatively, if the finishing time is of outright essentialness, with the useful resource of then less alters are key, but the resulting charge is most probable going to be higher. the base amount of rounds, Rmin, to reap (beneficial resource desires) feasibility is given through the decrease effective anticipated to allot the entire route of motion of solicitations. If only a solitary spherical is good enough, the model diminishes to that of phase II. In solicitation to decide the lower certain, we select $\mathrm{R}$ with the actual aim that the least viable sort of rounds to allocate the whole affiliation of solicitations is used. we find out what number of rounds are required to completely serve every benefit create's solicitations and pick the most outrageous of those rounds. therefore, $\mathrm{Rmin}=\max$ accurate sufficient $\in$ good enough $1 \mathrm{Dk} \mathrm{Bk} \mathrm{m}$, in which $\mathrm{Dk}, \mathrm{P} \mathrm{j} \in \mathrm{J}$ djk are the general enterprise needs for beneficial resource ok, $\mathrm{Bk}$, $\mathrm{Pi} \in \mathrm{I}$ bik are the complete furthest reaches of advantage $\mathrm{k}$, and [.] is used to demonstrate the rooftop work. the usage of lots less adjusts than Rmin isn't always appropriate enough to satisfy every solicitation necessity and therefore the hassle ends up infeasible. decrease interface factors of confinement yield extra acclimates to serve the requested useful resource needs. If the form organizer is busy with the maximum faded viable endorse dissemination price, best the most insignificant price interfaces need for use as a piece of every round. This project approach genuinely achieves a decrease mean rate curiously with the currently referenced one. anyhow, greater alters may be used. The number one form of rounds for this project route of motion, Rmax, is given through choosing the amount of rounds with the final goal that in every spherical we make use of best the most negligible rate useful resource and preserve up till the component that it all another time advances toward getting to be to be had. As such: Rmax = $\max$ adequate $\in$ adequate $\mathrm{Dk} b\left(\mathrm{I}^{\prime} \mathrm{k}\right) \mathrm{ok}$, in which I' good enough , argmin $i \in I$ (cikDk+ Fi). greater than Rmax range of rounds may be used, except the constitute challenge rate may not be moreover lessened, due to the reality using this device starting at now uses all the to be had most reduced charge sources in each spherical. The beyond assessment activates the going with case. recommendation. the quantity of rounds $\mathrm{R}$ for the multi-spherical SIA satisfies: $\mathrm{Rmin} \leq \mathrm{R} \leq \mathrm{R} \max$ (7) proof. famend $\mathrm{Dk}, \mathrm{Bk}$, and that $\mathrm{i}^{\prime}$ ok, as described as of now. If (3) can't be glad, with the beneficial resource of then the SIA is past the arena of imagination. For this circumstance, a workaround is to empower the undertaking to take place in a couple of round. In each round all the blessings are open for llotment. along the ones strains, extensively diagnosed there can be a first-rate range $\mathrm{Rk}>1$ to this sort of diploma, that bik $<$ Rkbik, $(\forall i \in I),(\forall$ okay $\in$ good enough) is huge and thusly (6) holds, which suggests that the multi-round SIA is possible. setting aijk = zero in (6) and keeping apart the $i^{\prime} s$ within the very last divergence yields: $\mathrm{Xj} \in \mathrm{JXi} \in \mathrm{I}$ xijk $\leq \mathrm{RkXi \in I}$ bik, ( $\forall$ okay $\in$ good enough) $(2) \Leftrightarrow P \mathrm{j} \in \mathrm{J} \mathrm{djk} P \mathrm{Pi} \in \mathrm{I}$ bik $\leq \mathrm{Rk},(\forall \mathrm{k} \in$ adequate) $\Leftrightarrow \mathrm{Dk} B \mathrm{Bk} \leq \mathrm{Rk}$, ( $\forall$ okay $\in$ okay). (eight) Letting Rk $=\lceil\mathrm{DkBk}\rceil$ is ideal sufficient to make (8) preserve. genuinely, the quality of those Rk's will fulfill (8) too. Alongside the ones traces, taking Rmin $=$ max okEadequate.Rk will make (8) preserve and multi-spherical SIA grow to be feasible. For the proper-hand component of (7), we're able to truely use the most prudent interface for every gain in every round. report I which interface gives the maximum shabby value for the entire solicitations of benefit ok. alongside these strains, absolutely $\mathrm{b}(\mathrm{i}$ adequate)ok of each gain adequate may be used as a piece of every round. on this way, $\Gamma \mathrm{Dk} b$ (I ' adequate)okay $\rceil$ rounds are required to serve the complete desires (Dk) for aid good enough, using the maximum modest interface in each round. From (8) and considering the way that b(i' proper sufficient)okay $\leq \mathrm{Pi} \in \mathrm{I}$ bik $=\mathrm{Bk},(\forall$ okay $\in \mathrm{ok})$, we've were given: $\mathrm{Dk} B k \leq \mathrm{Dk} b\left(\mathrm{i}{ }^{\prime}\right.$ good enough) $\mathrm{k} \leq \mathrm{R}^{\prime}$ ok, $(\forall \mathrm{k} \in \mathrm{k})$.) study that for this situation and at the same time as all is said in finished the ensuing segments for $\mathrm{R}=\mathrm{Rmin}$ can also go away lots much less extra factors of confinement conversely with $\mathrm{R}=\mathrm{Rmax}$, besides make a better general fee thinking about that severa solicitations are limited to be served from greater exorbitant interfaces with a selected authentic aim to keep $\mathrm{R}$ as low as is probably established. here, we first present the diversion includes fruition for the tool show we delineated in phase II. Survey that the form seem right here speaks to the SIA in oneround. events with extraordinary publications of movement of organizations and agency costs were reproduced to price the lead of the shape underneath various conditions. those events flow approximately as benchmarks to evaluate the execution of the estimations we displayed in phase III. The looking at consequences may be decided in subsection V-B. in the accompanying and ultimate subsection, we gift the era no longer on time consequences of multi-round SIA. In that, we devise each other direction of motion of era systems (organizations and authorization prices) to illustrate the impact of the amount of rounds to the entire charge of the problem [25-30].

\section{CONCLUSION}

We first gift the leisure takes area for the tool display we depicted in section II. Audit that the system display in that fragment speaks to the SIA in a single spherical. conditions with great courses of movement of organizations and incitation costs had been reproduced to apprehend the lead of the shape underneath numerous conditions. the ones conditions skip about as benchmarks to survey the execution of the figurings we supplied in phase III. The concerning results may be decided in subsection V-B. within the accompanying and final subsection, we gift the propagation not on time consequences of multi-round SIA. In that, we devise some different exercise plan of generation structures (corporations 
authorization fees) to expose the effect of the quantity of rounds to the overall fee of the hassle.

\section{REFERENCES}

[1] Gowri Sankaran, B., Karthik, B. \& Vijayaragavan, S.P. 2019, "Weight ward change region plummeting change for square based image huffman coding", International Journal of Innovative Technology and Exploring Engineering, vol. 8, no. 10, pp. 4313-4316.

[2] Gowri Sankaran, B., Karthik, B. \& Vijayaragavan, S.P. 2019, "Image compression utilizing wavelet transform", International Journal of Innovative Technology and Exploring Engineering, vol. 8, no. 10, pp. 4305-4308.

[3] Kandavel, N. \& Kumaravel, A. 2019, "Offloading computation for efficient energy in mobile cloud computing", International Journal of Innovative Technology and Exploring Engineering, vol. 8, no. 10, pp. 4317-4320.

[4] Vinoth, V.V. \& Kanniga, E. 2019, "Reversible data hiding in encrypting images-an system", International Journal of Engineering and Advanced Technology, vol. 8, no. 6, pp. 3051-3053.

[5] Selvapriya, B. \& Raghu, B. 2019, "Pseudocoloring of medical images: A research", International Journal of Engineering and Advanced Technology, vol. 8, no. 6, pp. 3712-3716.

[6] Senthil Kumar, K. \& Muthukumaravel, A. 2019, "Bi-objective constraint and hybrid optimizer for the test case prioritization", International Journal of Engineering and Advanced Technology, vol. 8, no. 6, pp. 3436-3448.

[7] Kavitha, G., Priya, N., Anuradha, C. \& Pothumani, S. 2019, "Read-write, peer-to-peer algorithms for the location-identity split", International Journal of Innovative Technology and Exploring Engineering, vol. 8, no. 9 Special Issue 3, pp. 445-447.

[8] Kaliyamurthie, K.P., Michael, G., Anuratha, C. \& Sundaraj, B. 2019, "Certain improvements in alzheimer disease classification using novel fuzzy c means clustering for image segmentation", International Journal of Innovative Technology and Exploring Engineering, vol. 8, no. 9 Special Issue 3, pp. 599-604.

[9] Kaliyamurthie, K.P., Sundarraj, B., Geo, A.V.A. \& Michael, G. 2019, "RIB: Analysis of I/O automata", International Journal of Innovative Technology and Exploring Engineering, vol. 8, no. 9 Special Issue 3, pp. 1019-1022.

[10] Velvizhi, R., Rajabhushanam, C. \& Vidhya, S.R.S. 2019, "Opinion mining for travel route recommendation using Social Media Networks (Twitter)", International Journal of Innovative Technology and Exploring Engineering, vol. 8, no. 9 Special Issue 3, pp. 508-512.

[11] Kavitha, R., Sangeetha, S. \& Varghese, A.G. 2019, "Human activity patterns in big data for healthcare applications", International Journal of Innovative Technology and Exploring Engineering, vol. 8, no. 9 Special Issue 3, pp. 1101-1103.

[12] Pothumani, S., Anandam, A.K., Sharma, N. \& Franklin, S. 2019, "Extended VEOT framework - Implemented in a smart boutique", International Journal of Innovative Technology and Exploring Engineering, vol. 8, no. 9 Special Issue 3, pp. 762-767.

[13] Kaliyamurthie, K.P., Michael, G., Krishnan, R.M.V. \& Sundarraj, B. 2019, "Pseudorandom techniques for the internet", International Journal of Innovative Technology and Exploring Engineering, vol. 8, no. 9 Special Issue 3, pp. 915-918.

[14] Aravindasamy, R., Jeffrin Rajan, M., Rama, A. \& Kavitha, P. 2019, "Deep learning provisions in the matlab: Focus on CNN facility", International Journal of Innovative Technology and Exploring Engineering, vol. 8, no. 9 Special Issue 3, pp. 990-994.

[15] Theivasigamani, S., Linda, M. \& Amudha, S. 2019, "Object sensing and its identification \& motion sensing", International Journal of Innovative Technology and Exploring Engineering, vol. 8, no. 9 Special Issue 3, pp. 545-549.

[16] Mary Linda, I., Vimala, D. \& Shanmuga Priya, K. 2019, "A methodology for the emulation of IPv4", International Journal of Innovative Technology and Exploring Engineering, vol. 8, no. 9 Special Issue 3, pp. 848-852.

[17] Velvizhi, R., Priya, D.J., Vimala, D. \& Linda, I.M. 2019, "Increased routing algorithm for mobile adhoc networks", International Journal of Innovative Technology and Exploring Engineering, vol. 8, no. 9 Special Issue 3, pp. 1606-1608.

[18] Sangeetha, S., Anuradha, C. \& Priya, N. 2019, "DNS in real world", International Journal of Innovative Technology and Exploring Engineering, vol. 8, no. 9 Special Issue 3, pp. 937-940.

[19] Geetha, C., Vimala, D. \& Priya, K.S. 2019, "Constructing multi-processors and spreadsheets with SKIVE", International Journal of Innovative Technology and Exploring Engineering, vol. 8, no. 9 Special Issue 3, pp. 516-519.

[20] Yugendhar, K., Sugumar, V. \& Kavitha, P. 2019, "A novel method of univac using fuzzy logic", International Journal of Innovative Technology and Exploring Engineering, vol. 8, no. 9 Special Issue 3, pp. 435-437.

[21] Kaliyamurthie, K.P., Michael, G., Elankavi, R. \& Jijo, S.A. 2019, "Implementing aggregate-key for sharing data in cloud environment using cryptographic encryption", International Journal of Innovative Technology and Exploring Engineering, vol. 8, no. 9 Special Issue 3, pp. 957-959.

[22] Jeffrin Rajan, M., Aravindasamy, R., Kavitha, P. \& Rama, A. 2019, "A novel method of object orientation variation in $\mathrm{C}++$ and java", International Journal of Innovative Technology and Exploring Engineering, vol. 8, no. 9 Special Issue 3, pp. 708-710.

[23] Nayak, R., Dinesh, S. \& Thirunavukkarasu, S. 2019, "A novel method improvement of rapid miner for the data mining applications", International Journal of Innovative Technology and Exploring Engineering, vol. 8, no. 9 Special Issue 3, pp. 457-460.

[24] Sivaraman, K., Krishnan, R.M.V., Sundarraj, B. \& Sri Gowthem, S 2019, "Network failure detection and diagnosis by analyzing syslog and SNS data: Applying big data analysis to network operations", International Journal of Innovative Technology and Exploring Engineering, vol. 8, no. 9 Special Issue 3, pp. 883-887.

[25] Vimala, D., Linda, I.M. \& Priya, K.S. 2019, "Decoupling online algorithms from erasure coding in DNS", International Journal of Innovative Technology and Exploring Engineering, vol. 8, no. 9 Special Issue 3, pp. 950-953.

[26] Rama, A., Kumaravel, A. \& Nalini, C. 2019, "Preprocessing medical images for classification using deep learning techniques", International Journal of Innovative Technology and Exploring Engineering, vol. 8 , no. 9 Special Issue 3, pp. 711-716.

[27] Sangeetha, S., Srividhya, S.R., Anita Davamani, K. \& Amudha, S. 2019, "A procedure for avoid overrun error in universal synchronous asynchronous receiver transmitter (usart) by utilizing dummy join and interrupt latency method", International Journal of Innovative Technology and Exploring Engineering, vol. 8, no. 9 Special Issue 3, pp. 657-660

[28] Aravindasamy, R., Jeyapriya, D., Sundarajan, B. \& Sangeetha, S 2019, "Data duplication in cloud for optimal performance and security", International Journal of Innovative Technology and Exploring Engineering, vol. 8, no. 9 Special Issue 3, pp. 1156-1158

[29] Aravindasamy, R., Jeffrin Rajan, M., Sugumar, V. \& Kavitha, P. 2019, "A novel method on developing superblocks and the transistor using apodryal", International Journal of Innovative Technology and Exploring Engineering, vol. 8, no. 9 Special Issue 3, pp. 982-985.

[30] Sasikumar, C.S. \& Kumaravel, A. 2019, "E-learning attributes selection through rough set theory and data mining", International Journal of Innovative Technology and Exploring Engineering, vol. 8, no. 10 , pp. $3920-3924$ 


\section{AUTHORS PROFILE}

C. Geetha Assistant Professor, Department of Computer Science \& Engineering, Bharath Institute of Higher Education and Research, Chennai, India

S. Kavitha, Assistant Professor, Department of Computer Science \& Engineering, Bharath Institute of Higher Education and Research, Chennai, India

C. Nalini, Assistant Professor, Department of Computer Science \& Engineering, Bharath Institute of Higher Education and Research, Chennai, India 